\title{
LTCC-Integrated Dielectric Resonant Antenna Array for 5G Applications
}

\author{
Mohsen Niayesh * (D) and Ammar Kouki \\ Electrical Engineering Department, Ecole de Technologie Superieure (ETS), Montreal, QC H3C 1K3, Canada; \\ ammar.kouki@etsmtl.ca \\ * Correspondence: mohsen.niayesh@lacime.etsmtl.ca
}

check for updates

Citation: Niayesh, M.; Kouki, A. LTCC-Integrated Dielectric Resonant Antenna Array for 5G Applications. Sensors 2021, 21, 3801. https:// doi.org/10.3390/s21113801

Academic Editor: Andrea Randazzo

Received: 15 April 2021

Accepted: 26 May 2021

Published: 31 May 2021

Publisher's Note: MDPI stays neutral with regard to jurisdictional claims in published maps and institutional affiliations.

Copyright: (c) 2021 by the authors. Licensee MDPI, Basel, Switzerland. This article is an open access article distributed under the terms and conditions of the Creative Commons Attribution (CC BY) license (https:// creativecommons.org/licenses/by/ $4.0 /)$.

\begin{abstract}
A millimeter-wave dielectric resonator antenna array with an integrated feeding network and a novel alignment superstrate in Low Temperature Cofired Ceramics (LTCC) technology is presented. The antenna array consists of 16 cylindrical DR antenna (CDRA) elements operating at $28 \mathrm{GHz}$ for mm-Wave $5 \mathrm{G}$ applications. The array is fed by an inverted microstrip corporate feeding network designed and built in the same LTCC stack as the resonators. A grooved and grounded superstrate is introduced to facilitate the alignment of the individual array elements while enhancing the overall performance of the antenna array. The performance of the proposed stack is evaluated numerically and compared with measured data. Measured results show an impedance bandwidth of $9.81 \%$ at $28.72 \mathrm{GHz}$ with a maximum realized gain of $15.68 \mathrm{dBi}$ and an efficiency of $88 \%$, and are in excellent agreement with simulations.
\end{abstract}

Keywords: millimeter wave (mm-Wave); dielectric resonant antenna (DRA); fifth generation (5G); array antenna; corporate feeding network; multi-layered technology; low-temperature cofired ceramics (LTCC)

\section{Introduction}

Millimeter-wave (mm-Wave) frequency bands have been selected for 5G applications as a response to the demand for higher data transmission rates in wireless communications. One of the challenges in these bands is the increased link loss due to the reduced wavelength and atmospheric absorption. Consequently, mm-Wave antenna systems are required to provide high gain and high efficiency [1-11]. Various approaches and implementations of radiating elements have been proposed for the mm-wave frequency bands, including flexible antennas [6,7], 3D printed antennas [1,11], microstrip patches and slots $[2,4,8-10]$ and conventional DRAs on printed circuit board (PCB) technology [3,5,9]. Printed antennas, i.e., patches and slots, are intrinsically narrowband and suffer from conductor losses as well as the likely excitation of surface waves, both of which lead to lower efficiency. Different approaches have been proposed to increase bandwidth, such as using multiple layer stacks, perfect magnetic conductors (PMC) and defective grounds [12-14]. Others have focused on reducing losses associated with surface waves $[15,16]$. Still, the bandwidth and efficiency performance of these antennas remain limited. On the other hand, dielectric resonant antennas (DRAs) can provide high efficiency and relatively wide bandwidth [17]. Indeed, DRAs have witnessed significant developments in the last decade and have become a promising candidate for higher frequency applications, such as mm-Wave 5G due to their compact size, high power handling capability and potential broadband response [18]. Compared to planar (multilayer) antennas, DRAs can offer better bandwidth and efficiency but are generally costlier and require a more involved fabrication process [17].

DRAs consist of volumetric dielectric structures that are excited via an electromagnetic coupling mechanism, such as a microstrip line, an aperture in a conducting plane or a feeding probe $[3,19,20]$. Many efforts have been deployed to improve the bandwidth and gain of a single DRA element such as Mrnka and Raida [21] and Ta and Park [22]. One of the 
ways to increase the gain is exciting higher-order resonator modes [21,23]. These techniques have led to gain, efficiency and bandwidth performance that are better than the printed antennas. However, using DRAs with standard PCB fabrication technology can be sensitive to tolerances during the machining of the resonators themselves and, more frequently, to tolerances when aligning and shaping the resonators with the feeding structure on the PCB. This becomes even more critical at higher frequencies where high alignment precision and tight size tolerances are required to avoid performance degradation. For instance, in Abdallah et al. [20], due to the fabrication process, a frequency shift of $1.5 \mathrm{GHz}$ and a reduction in gain of $2.5 \mathrm{~dB}$ at the desired resonant frequency of the designed DRA were reported and attributed to fabrication and assembly. To address DRA cost, machining precision, and alignment tolerances, while maintaining good performance, the use of Low Temperature Cofired Ceramics technology (LTCC) for DRA fabrication and integration can provide a viable solution. Indeed, LTCC facilitates the fabrication of DRA-based antenna systems and their direct integration with other front-end circuits, e.g., [24,25], in a single process. An initial demonstration of this concept was proposed by Niayesh and Kouki [26] where a single DRA element was fabricated in LTCC for operation at the X-band. Although good results were achieved, the proposed design was found not to be suitable for use at higher frequencies because it was based on probe feeding, which presents fabrication and alignment challenges in an array context at such frequencies.

In this paper, an efficient LTCC-based dielectric resonator antenna array with aperture feeding suitable for mm-wave frequencies and 5G applications is presented. The array is fabricated in a single LTCC process with a new custom layer stack that provides highly precise dimensioning and alignment. The proposed structure provides a wide bandwidth, stable gain over the operating frequency band and high radiation efficiency. The organization of this paper is as follows. In Section 2 the design of the proposed single element DRA is discussed. In Section 3, the antenna array design procedure, including the antenna array configuration and feeding network, is presented and with numerical and measurement results of the proposed array. Section 4 concludes this paper.

\section{Single Element DRA Design}

In this section, the design of a single element Cylindrical Dielectric Resonator Antennas (CDRA) using LTCC technology is presented. First, a conventional design approach, similar to that with standard PCBs, is used, whereby the DR and the substrate are both made out the same ceramic material but aligned manually with limited precision. Second, a new design is proposed whereby the alignment precision is addressed through the introduction of a grooved superstrate ceramic layer. In both designs, the LTCC material used is the Ferro A6M green tape with $\varepsilon_{r}=5.8$ and loss tangent of 0.001 . All conductors are made of silver $\left(\sigma=6.1 \times 10^{7} \mathrm{~S} / \mathrm{m}\right)$ with a thickness of $8 \mu \mathrm{m}$. The basic theory behind the design of DRAs is well developed by Petosa [27] and consists mainly of dimensioning the resonator, usually in a cylindrical shape, although other shapes have been proposed [28-30], such that a given mode is excited, usually a hybrid HE or an EH mode.

\subsection{Conventional CDRA Design in LTCC}

The conventional single element CDRA design consists of a cylindrical resonator, typically a high-dielectric ceramic $[17,28]$, placed on top of the ground plane of a PCB substrate, typically made of organic material [17], with one of many different feeding mechanisms $[17,28,31]$. Here, we propose to follow the same procedure as the conventional design method, but using the LTCCs as both the ceramic of the cylindrical resonator and the grounded substrate on which it is placed. We further choose a feeding mechanism consisting of an inverted microstrip line that couples to the resonator through an aperture, of dogbone shape in the ground plane as illustrated by the side view in Figure 1 and the top schematic view in Figure 2. The design parameters consist of the substrate's height, $h_{s u b}$, the resonator's radius, $r_{D R}$, and height, $h_{D R}$, the feeding line's width, $w_{f}$, the dogbone 
slot's dimensions, $W_{\mathrm{s}}, L_{s r m}$, and $W_{s r m}$, and the off-set of the slot from the end of the feeding line, $L_{\mathrm{of}}$.

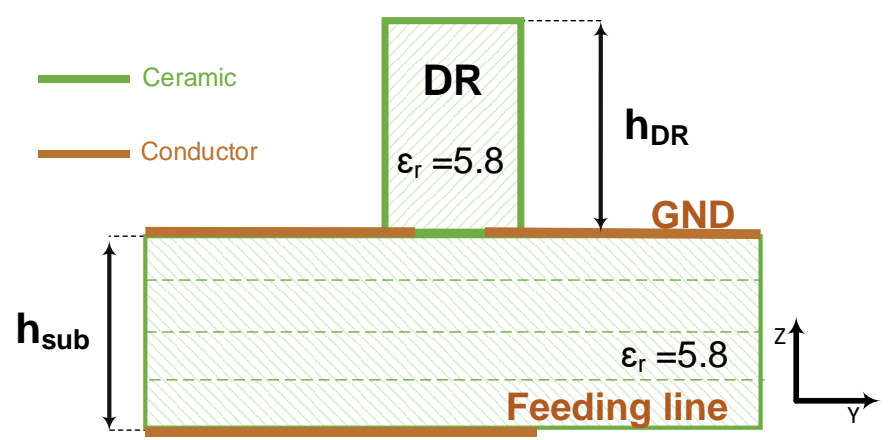

Figure 1. The schematic stack for single element CDRA.

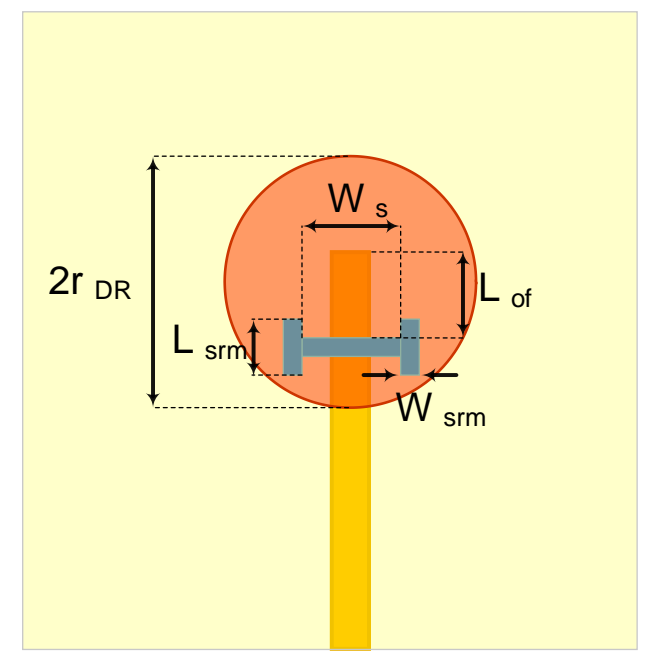

Figure 2. The schematic of the proposed single element CDRA (top view).

In order to achieve a large bandwidth and a broad radiation pattern, we first dimensioned the DR such that it would resonate in the $\mathrm{HEM}_{11 \delta}$ mode at $29.5 \mathrm{GHz}$, the center frequency of the band, with $\varepsilon_{r}=5.8$. Based on Petosa [27], we chose $r_{D R}$ and found it to be $2.5 \mathrm{~mm}$. Next, we the closed form expression for the resonant frequency, $f_{\mathrm{r}}$ [32]:

$$
f_{r}=\frac{c}{2 \pi r_{D R} \sqrt{\varepsilon_{r}}}\left[1.71+\left(\frac{r_{D R}}{h_{D R}}\right)+0.1578\left(\frac{r_{D R}}{h_{D R}}\right)^{2}\right]
$$

We found the value of $h_{D R}=1.02 \mathrm{~mm}$. These values, $r_{D R}=2.5 \mathrm{~mm}$ and $h_{D R}=1.02$, are used as the initial dimensions for the DR and were then optimized numerically by using the eigen-mode solver in HFSS to ensure that the HEM $11 \delta$ mode resonated at $29.5 \mathrm{GHz}$. This optimization yields a DR radius of $1.95 \mathrm{~mm}$ and a height of $1.45 \mathrm{~mm}$ with a mode distribution of the magnetic field as illustrated in Figure 3. The substrate is made of four 5-mil LTCC sheets to ensure mechanical robustness. This leads to a fired substrate thickness, $h_{\text {sub }}$, of $0.5 \mathrm{~mm}$ and a $50 \Omega$ inverted microstrip line width, $w_{f}$, of $1.75 \mathrm{~mm}$. The slot shape, dimensions and position were optimized to excite the $\mathrm{HEM}_{11 \delta}$ mode and performance. The slot width, Ws, controls the level of coupling between the microstrip and the DR while the proper values of $L_{s r m}$ and $W_{s r m}$ ensured the best uniformity of the mode distribution [33]. The offset of the slot from the end of the microstrip line, $L_{o f f}$, was used to tune the matching. The optimal values of all these parameters were summarized in Table 1 and were obtained by optimization in HFSS that maximized the gain and bandwidth and minimized the return loss. 

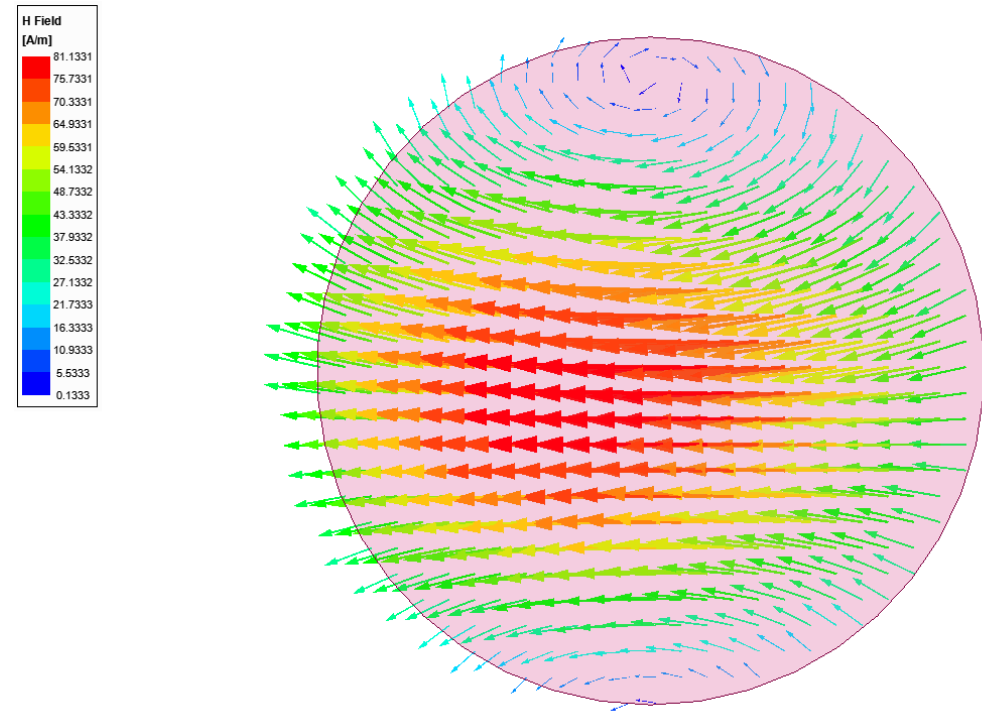

Figure 3. Magnetic field distribution of the resonant $\mathrm{HEM}_{11 \delta}$ mode in the proposed single element CDRA obtained from an eigenmode solution.

Table 1. Design parameters of the proposed single element CDRA.

\begin{tabular}{ccc}
\hline Parameters & Value (mm) & Description \\
\hline$L s r m$ & 0.5 & Slot arm length \\
\hline$W s r m$ & 0.2 & Slot width \\
\hline$W_{s}$ & 1.75 & Slot length \\
\hline$L o f$ & 1 & Offset length \\
\hline$r D R$ & 1.95 & Dielectric radius \\
\hline$h D R$ & 1.45 & Dielectric height \\
\hline$h s u b$ & 0.50 & Substrate thickness \\
\hline$w_{f}$ & 1.75 & Microstrip width \\
\hline
\end{tabular}

Figure 4 shows the magnetic field distribution in the DR with the optimized feeding structure at the center frequency of $29.5 \mathrm{GHz}$, which is found to be very close to the desired eigenmode of Figure 3. Figure 5 illustrate the gain profile for the conventional CDRA designed with LTCC at the center frequency of $29.5 \mathrm{GHz}$.
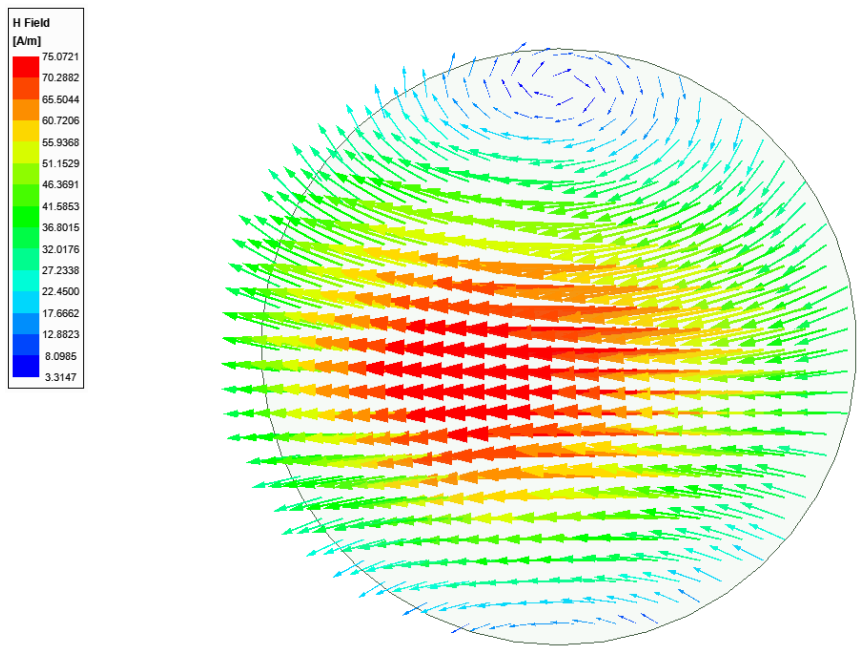

Figure 4. Excited near-HEM $\mathrm{H}_{11 \delta}$ mode with the designed feeding structure of the CDRA. 


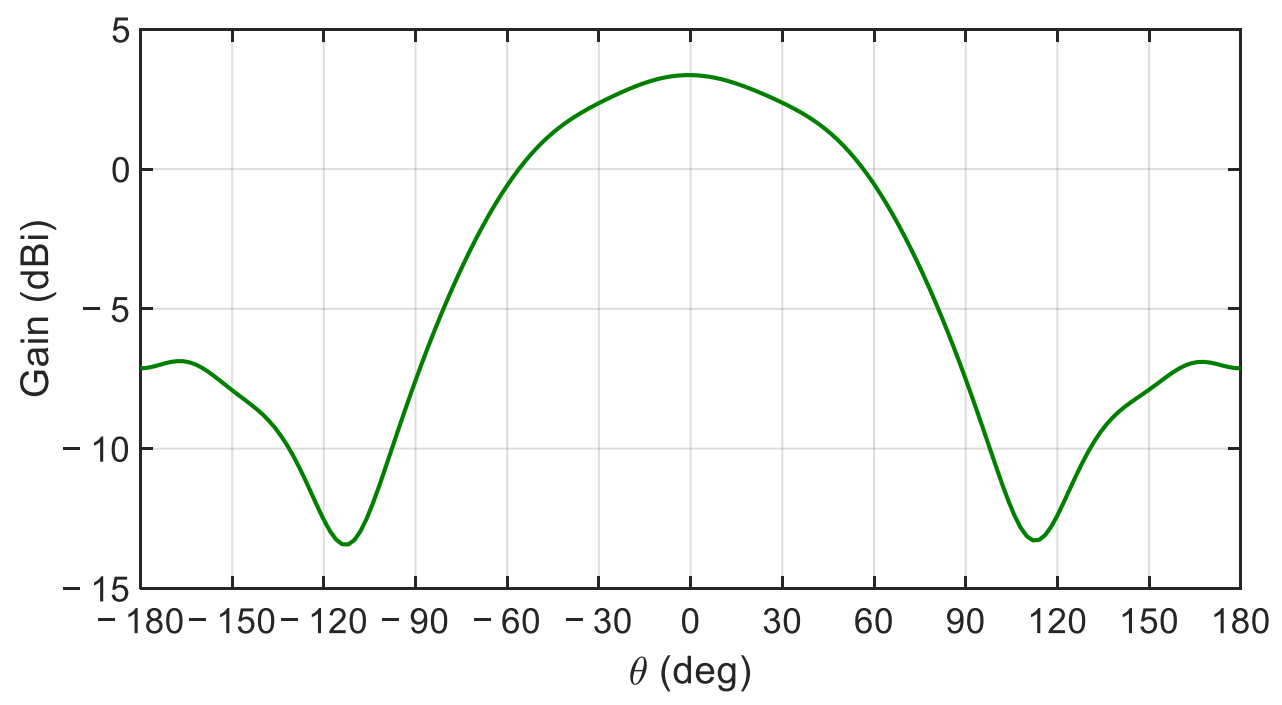

Figure 5. Simulated gain profile for the conventional CDRA design in LTCC at $29.5 \mathrm{GHz}$.

\subsection{New CDRA Design with a Grooved Superstrate}

In the conventional CDRA design, the placement of the DR on top of the ground plane, where the radiation slot is located, is done manually, which leads to alignment precision issues that can easily impact the antenna gain and/or bandwidth. This issue can be compounded in an array setting. To tackle this issue, we propose a new LTCC stack, which consists of the stack of the conventional design on top of which a grooved superstrate, i.e., an additional LTCC layer with a hole, is added as shown in Figure 6. The groove is a precision laser milled during the LTCC fabrication process to generate a groove which is the exact size of the DR, within a $5 \mu \mathrm{m}$ tolerance.

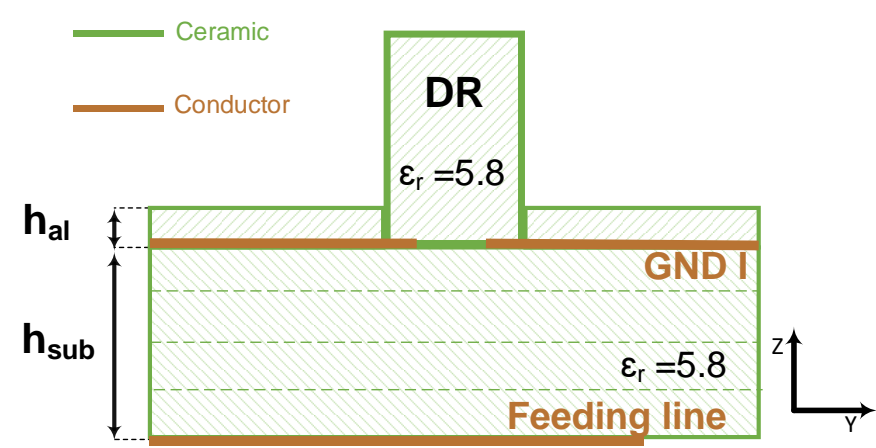

Figure 6. Schematic of the proposed stack with a grooved superstrate for the CDRA.

This new design allows for easy and precise alignment, however, as can be seen in Figure 7, it reduces the gain and deteriorates the front to back ration (FTBR) due to the excitation of the surface wave modes. Indeed, the gain is reduced by $0.46 \mathrm{~dB}$, while the FTBR is degraded to $7.68 \mathrm{~dB}$, down from $9.23 \mathrm{~dB}$ for the conventional CDRA stack. This behavior is to be expected, since for a conductor backed dielectric slab of thickness $d$ and relative permittivity $\varepsilon_{r}, \mathrm{TM}_{n}$ and $\mathrm{TE}_{n}$ modes can be excited, with cutoff frequencies given by Pozar [34]:

$$
\begin{aligned}
& f_{c_{T M}}=\frac{n c}{2 d \sqrt{\varepsilon_{r}-1}}, \text { for } n=0,1,2, \ldots \\
& f_{c_{T E}}=\frac{(2 n-1) c}{4 d \sqrt{\varepsilon_{r}-1}}, \text { for } n=1,2,3, \ldots
\end{aligned}
$$




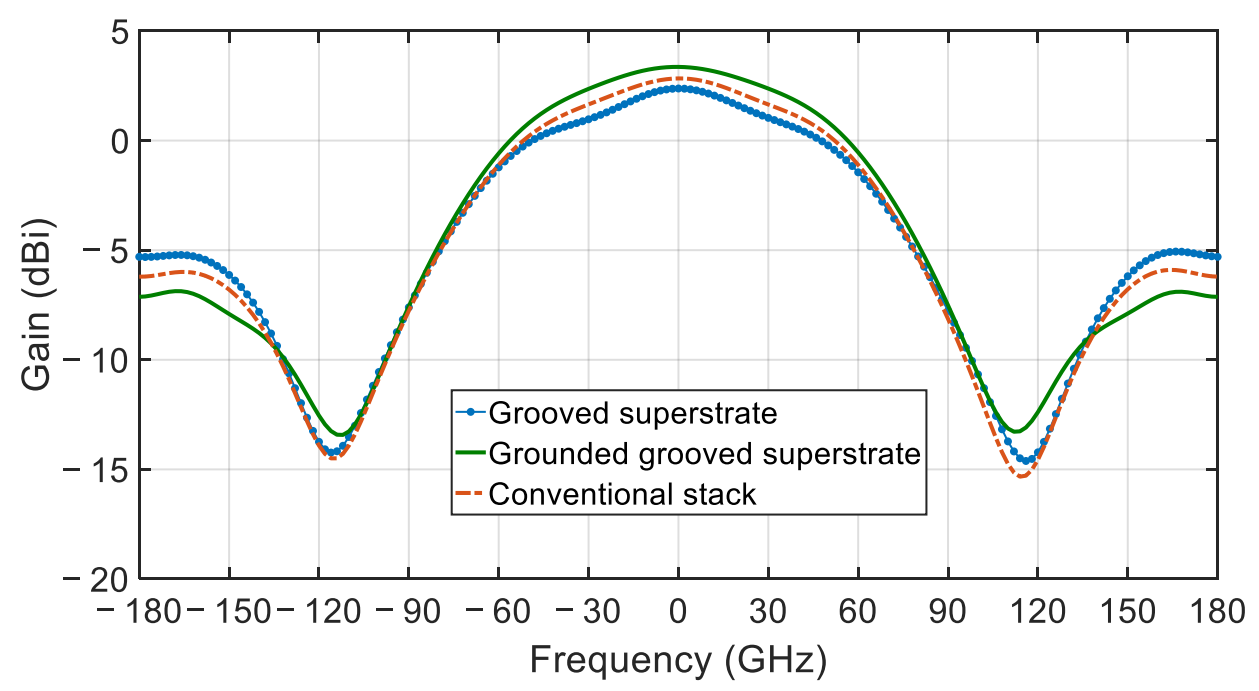

Figure 7. Comparison of the simulated gain profile for the single element CDRA for conventional, grooved superstrate and the grounded grooved superstrate stack.

To eliminate all TE and TM modes having an index $n \geq 1$, the thickness of the dielectric layer should be chosen such that $\mathrm{TE}_{1}$ is cut off at $31 \mathrm{GHz}$, the highest frequency in the considered band. This determines the maximum thickness that can be utilized as a superstrate. Here, we chose a superstrate thickness of $h_{a l}=0.03 \mathrm{~mm}$ corresponding to the thinnest available green sheet of LTCC Ferro A6M. This thickness ensures that all higher order modes are cut off while having minimum impact on the performance of the antenna. To eliminate the $\mathrm{TM}_{0}$ mode, which has no cutoff frequency, an additional ground plane is added to the top surface of the alignment superstrate and then the two ground planes (GND I and GND II) are connected with multiple vias as shown in Figure 8. Via fencing around the aperture is used as it prevents any radiation leakage from the sides in addition to ensuring that the two ground planes are connected. Consequently, the excitation efficiency is increased, and the total radiation efficiency is improved.

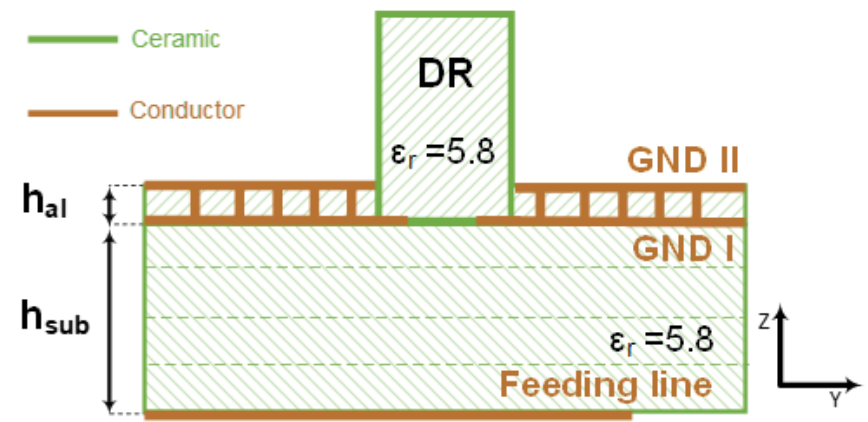

Figure 8. Schematic of the proposed stack with grounded and grooved superstrate for the CDRA.

Figure 7 compares the gain profile of the CDRA when designed using the conventional stack, the grooved superstrate and the grounded grooved superstrate. As can be seen, the grounded grooved superstrate helps to eliminate the surface wave modes yielding an increase in gain by $1 \mathrm{~dB}$ over the CDRA with the grooved superstrate. When compared to the conventional CDRA, the grounded grooved superstrate yield a gain improvement of $0.53 \mathrm{~dB}$, while enhancing the FTBR to $10.48 \mathrm{~dB}$ from $9.23 \mathrm{~dB}$.

Figure 9 compares the realized gain variation over the considered frequency band of the proposed single element antenna for the convectional stack and the grounded and grooved superstrate. 


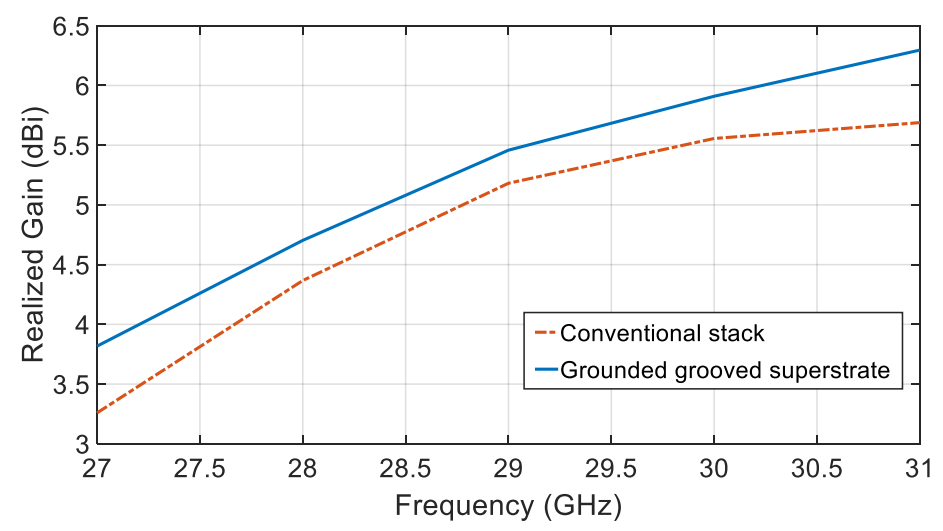

Figure 9. Realized gain profile for the single element CDRA for the two proposed stack over the operational frequency.

Figure 10 illustrates the return loss for the proposed single element CDRA and compares the performance with the conventional method. It is shown that the bandwidth of $18.1 \%$ is achieved with the modified stack. The resonant frequency is designed to be centered at $29.48 \mathrm{GHz}$ for the single element CDRA and there is a slight frequency shift between the conventional LTCC stack and the proposed modified LTCC stack.

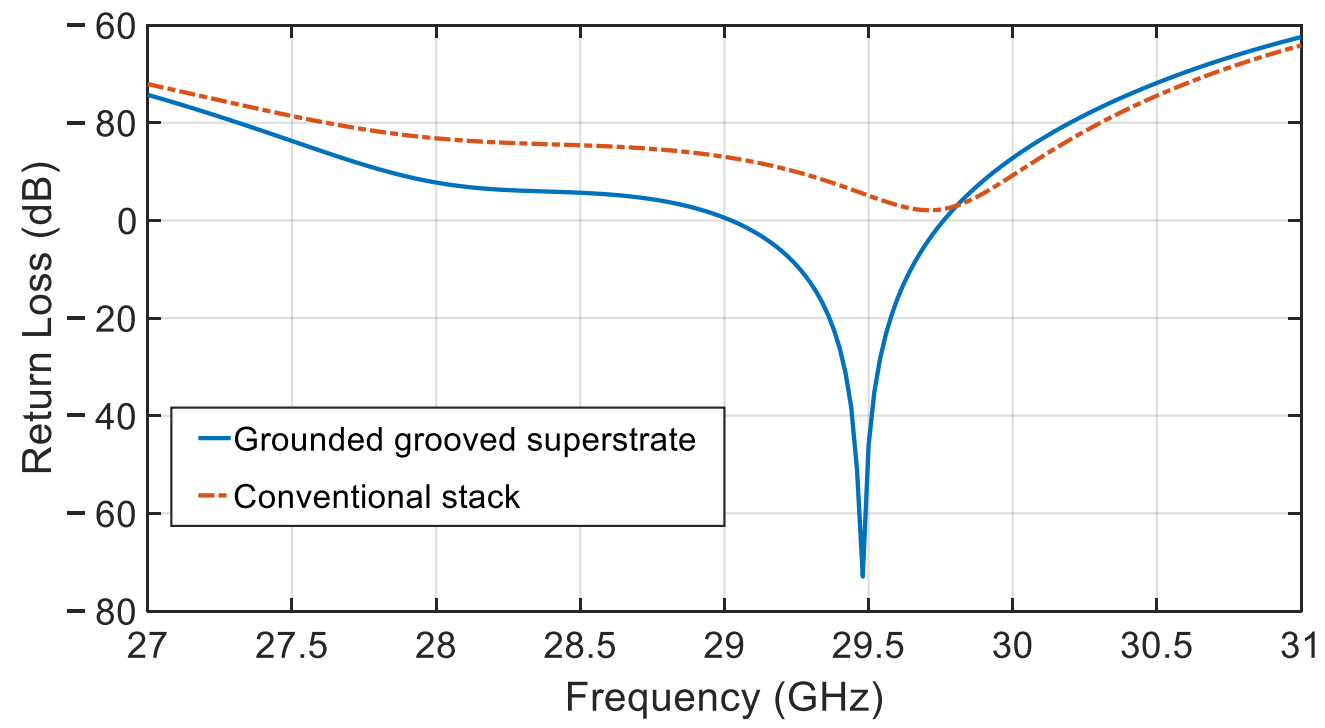

Figure 10. Return loss for the single element CDRA.

\section{Antenna Array Design}

\subsection{Geometric Arrangement of Array Elements}

The proposed single element CDRA with grooved superstrate and dogbone coupling slot in the previous section is used to build a $4 \times 4$ rectangular array. The DRA elements are placed on top of the ground plane with a center-to-center distance of $S$, to be determined. The coupling slot dimensions are kept the same, while a corporate feeding network is added to feed each slot. Figure 11 illustrates the geometric arrangement of array elements with the feeding network underneath. 


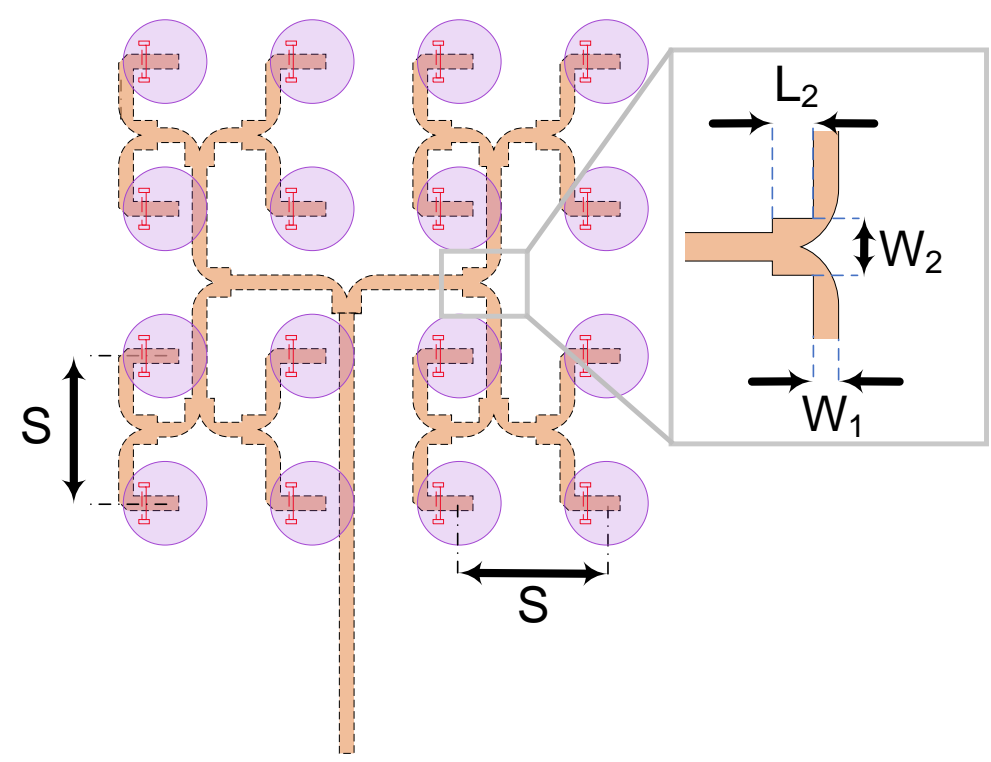

Figure 11. Feeding network schematic (ground plane hidden).

\subsection{Inter-Element Spacing}

One of the key parameters for designing the arrays of radiating elements is the interelement spacing and the mutual coupling between adjacent elements that results from this spacing. This coupling will impact the radiation pattern, the appearance of grating lobes and the impedance matching. These characteristics cannot be predicted by array factor principals alone and must be taken into account by precise field analysis. While mutual coupling in DRAs is low compared to other types of arrays like patch arrays, they must still be taken into account in the design. To determine the optimal inter-element spacing for our array design, we carried out field simulations for a varying inter-element spacing, $S$, starting from $S=4.5 \mathrm{~mm}\left(0.38 \lambda_{0}\right)$ to $S=10 \mathrm{~mm}\left(0.97 \lambda_{0}\right)$ and computed the resulting gain as shown in Figure 12. A maximum gain of $15.68 \mathrm{dBi}$ was achieved for $S=7 \mathrm{~mm}$ $\left(S=0.67 \lambda_{0}\right)$. For $S$ larger than $7 \mathrm{~mm}$, grating lobes occur, resulting in a reduced gain.

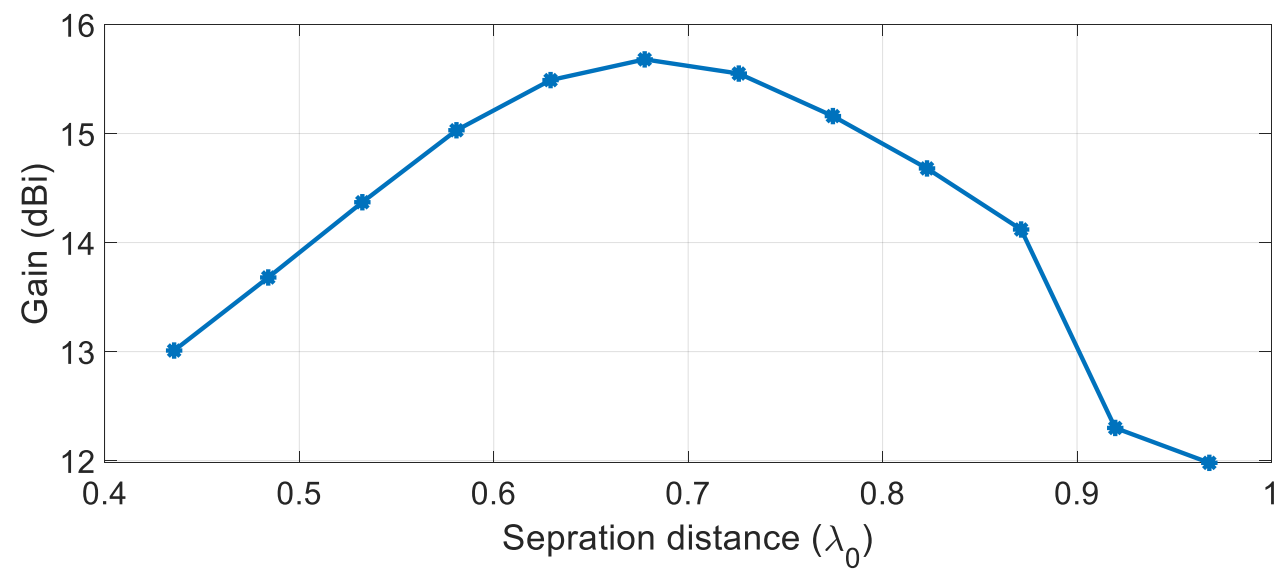

Figure 12. The gain profile variation for different inter-element spacing.

\subsection{Feeding Network Design}

To achieve uniform excitation of all array elements, a corporate feeding network is chosen using the same LTCC stack. We used the inverted microstrip technology for simplicity and ease of implementation, though alternative lower loss guiding structures could be contemplated, i.e., SIW. The schematic of the proposed corporate feeding network is illustrated in Figure 12. The network is composed of multiple quarter-wave matched T-junctions. Each junction is made of a $50 \Omega$ input line of width $W_{1}=0.7 \mathrm{~mm}$ connected 
to two $50 \Omega$ output branches of the same width through a $35.5 \Omega$ quarter wavelength transformer of width $W_{2}=1.4 \mathrm{~mm}$ and length $L_{2}=1.13 \mathrm{~mm}$. A round chamfer of the $50 \Omega$ output lines is introduced to improve bandwidth coverage and a chamfer radius of $0.7 W_{1}$ is found to yield optimal performance. Based on this design, the entire array with its feeding network fits into a square area the of size $25 \times 25 \mathrm{~mm}^{2}$. However, to achieve a good FTBR value, i.e., better than $10 \mathrm{~dB}$, while maintaining a compact size, the dimension of the ground plane must be optimized. An overall size of $46 \times 46 \mathrm{~mm}^{2}$ is for the ground plane found to yield an FTBR of $11 \mathrm{~dB}$ and is selected for the fabrication. The array has been modeled and simulated with a full-wave simulator, Ansys HFSS. To ensure the highest accuracy when comparing it to measurements, a K-connector model was included in the simulation along with all dielectric and conductor losses. The simulation results of the designed array are presented in the next section and compared to the measured data.

\section{Results and Discussion}

The designed antenna array, including the feeding network and the dielectric resonator pucks, have been fabricated with the same LTCC stack [35]. Figure 13 shows pictures of the top and bottom sides of the fabricated antenna array. To measure the array's performance without the effects of the connector, a TRL (Through, Reflect, Line) calibration technique was used where the K-connector and a short section of the inverted microstrip line were used to build the three TRL kit standards. To ensure an accurate comparison between simulation and measurement results, the simulated data were de-embedded from the K-connector's plane to the same plane of the reflect standard of the TRL kit.

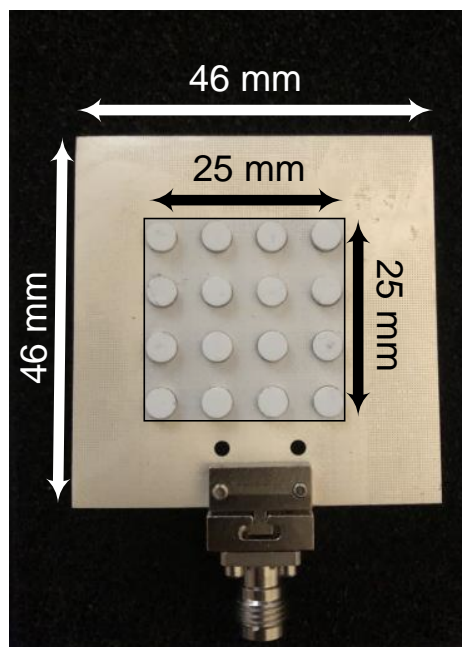

(a) Top view.

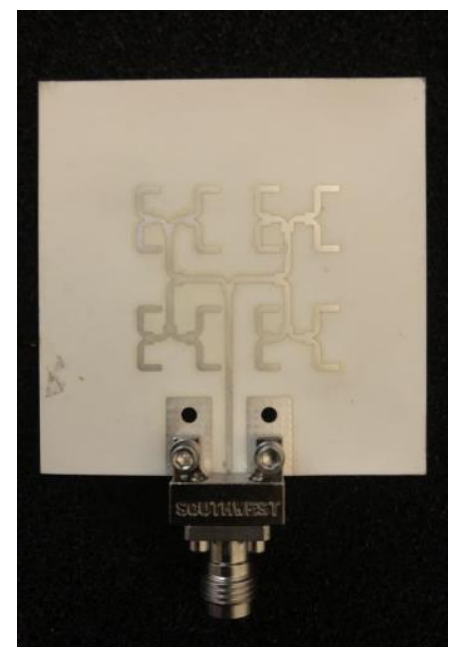

(b) Bottom view.

Figure 13. Fabricated DRA array antenna.

Figure 14 shows the simulated and measured results for the return loss of the array antenna. The measurement data have a slight frequency shift of $\sim 0.2 \mathrm{GHz}$, compared to the simulation results, which may be due to minor imperfections during fabrication and / or a slight variation in the LTCC shrinkage during firing from the nominal values used in simulations. As shown, the measured $10 \mathrm{~dB}$ bandwidth of the antenna is $2.75 \mathrm{GHz}$, resulting in a fractional bandwidth of $9.81 \%$ around the resonant frequency of $28.52 \mathrm{GHz}$. 


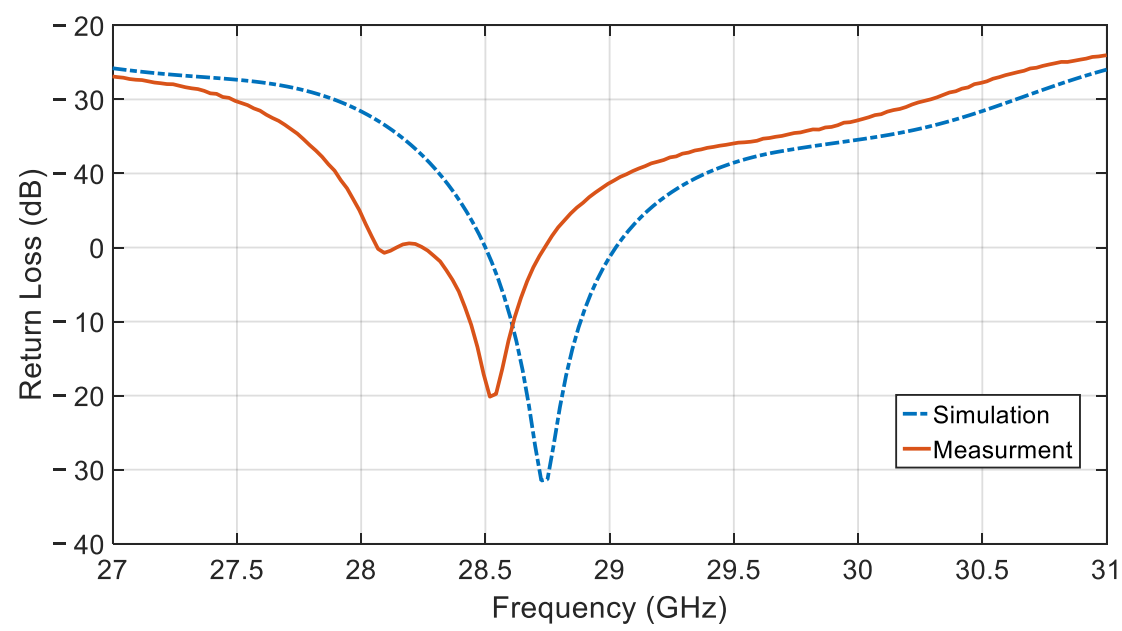

Figure 14. Return loss versus frequency of the proposed antenna array.

The simulated normalized gain profile of the proposed antenna array for the E- and H-planes at the center frequency is depicted in Figure 15. Figure 16 compares the simulated and measured realized gain pattern for the array at the measurement's center frequency of 28.72 GHz. Overall, good agreement is observed at this frequency. The simulated $15.68 \mathrm{dBi}$ and the measured $15.59 \mathrm{dBi}$ gain values are virtually identical.

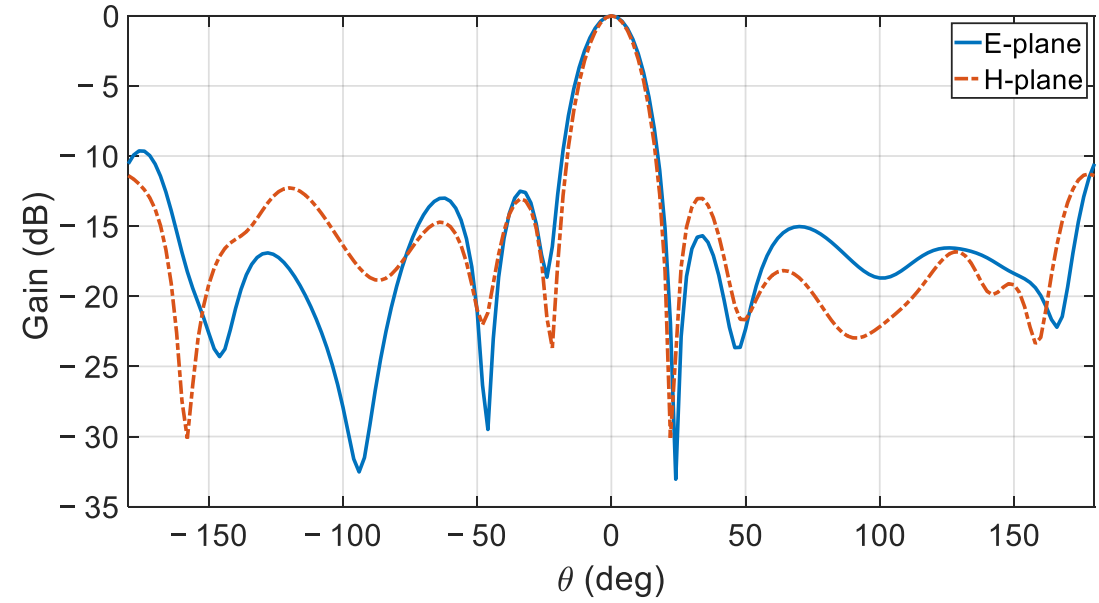

Figure 15. E- and H-plane radiation pattern at $28.52 \mathrm{GHz}$ for the proposed CDRA array.

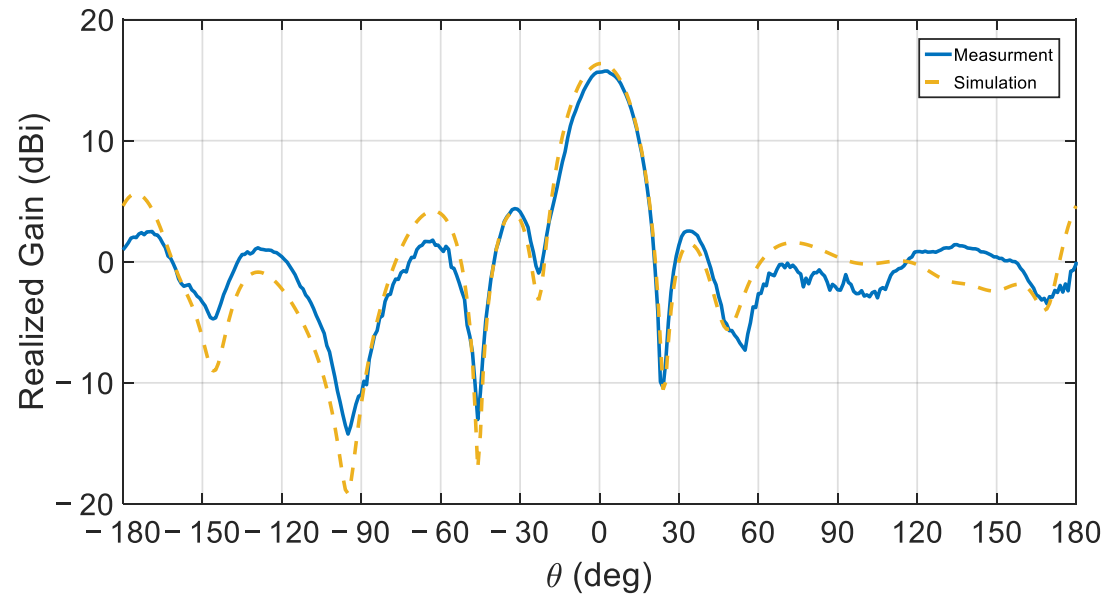

Figure 16. The simulated and measured radiation pattern of the CDRA array at $28.72 \mathrm{GHz}$. 
Additional comparisons between the simulated and measured radiation patterns are presented in Figure 17, simulations, and Figure 18, measurements, at different frequencies. The agreement between measurements and simulations is excellent around the center frequency with a gain difference of less than $\pm 0.15 \mathrm{~dB}$, but deteriorates slightly towards the band edges where the maximum gain difference reaches $\pm 1.24 \mathrm{~dB}$.

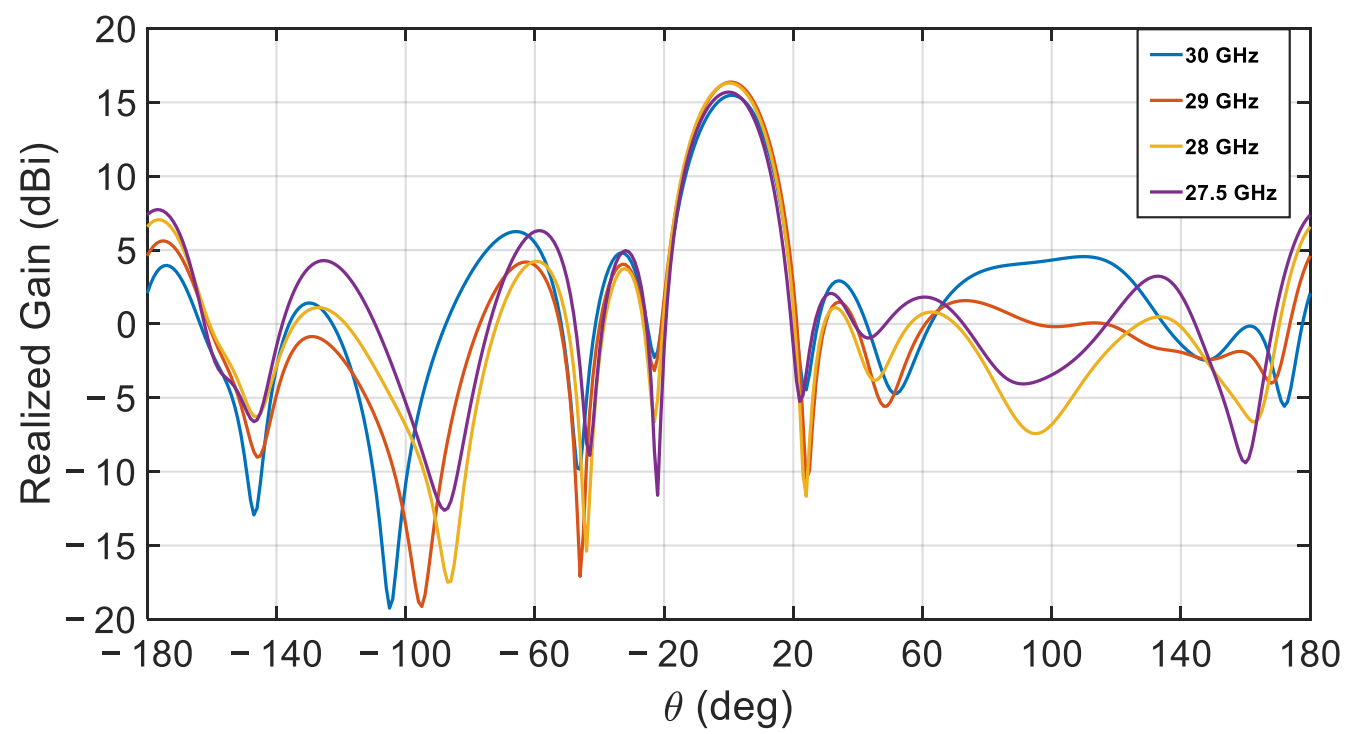

Figure 17. Simulated realized gain for the proposed CDRA array.

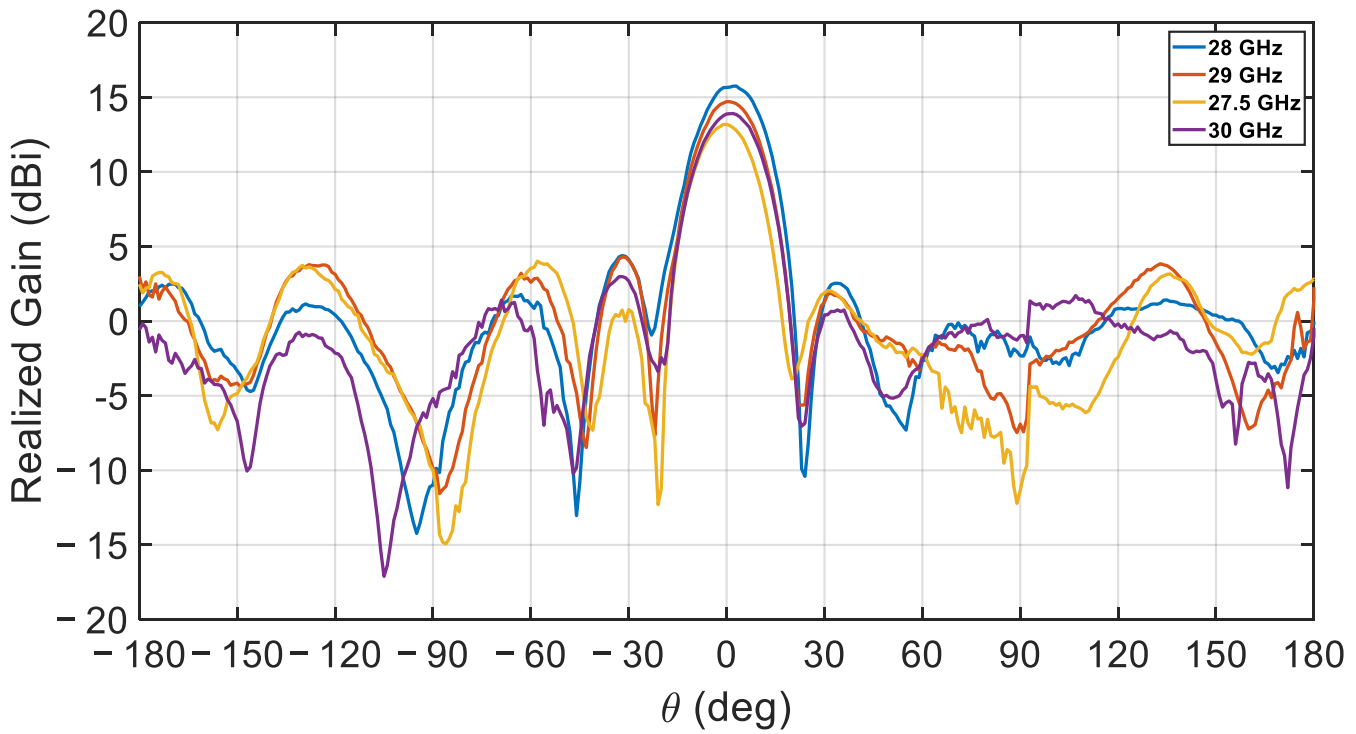

Figure 18. Measured realized gain for the proposed CDRA array.

Figure 19 shows the variation of the measured efficiency of the proposed $4 \times 4$ CDRA array versus frequency at discrete points. A maximum efficiency of $88 \%$ has been achieved around $28.5 \mathrm{GHz}$ and is at or above $85 \%$ between 27.5 and $30 \mathrm{GHz}$. 


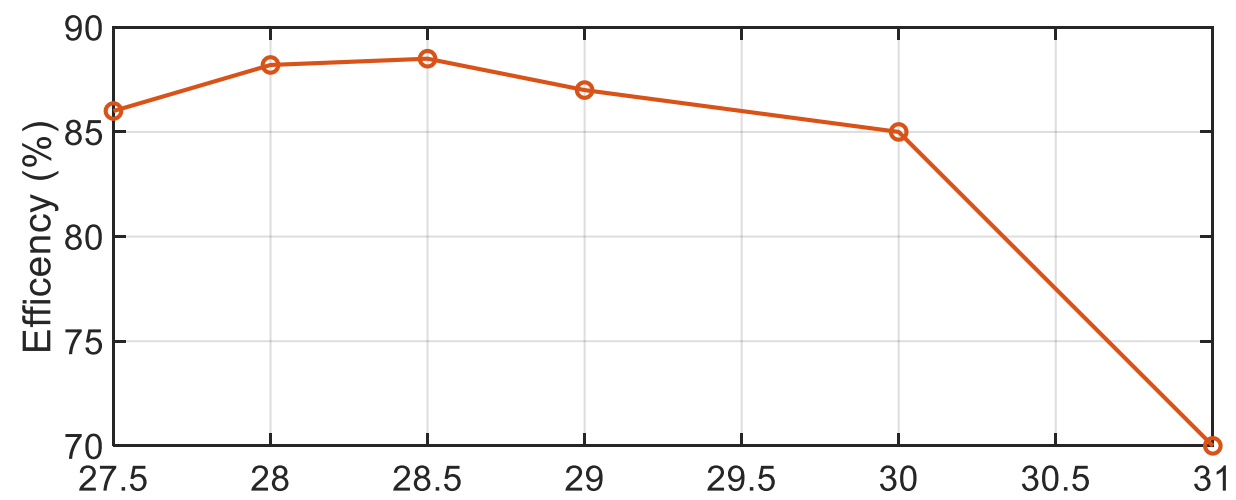

Figure 19. Measured radiation efficiency for the proposed CDRA antenna array.

Table 2 summarizes the performance metrics of the presented DRA array and lists them alongside other DRA, microstrip patch antenna structures operating at mm-wave frequency bands in the literature. The proposed antenna array has a good gain and impedance bandwidth as well as a high efficiency, despite using a microstrip-type feeding network. Unlike all the other works, the proposed array is entirely fabricated in LTCC technology and used the novel grounded and grooved superstrate to achieve ease fabrication and alignment with improved gain and reduced FTBR.

Table 2. Summary of performance of the proposed array alongside some of other reported antenna arrays in the literature.

\begin{tabular}{|c|c|c|c|c|c|c|}
\hline \multicolumn{2}{|c|}{ Ref. } & Center Frequency (GHz) & Bandwidth (\%) & Gain (dBi) & Efficiency (\%) & Elements \\
\hline \multicolumn{2}{|c|}{ This work } & 28.7 & 9.81 & 15.68 & 88 & 16 \\
\hline \multirow{4}{*}{ DRA } & {$[36]$} & 36.7 & 6.81 & 12 & 91 & 12 \\
\hline & [3] & 25.7 & 1.16 & 16.3 & 74 & 4 \\
\hline & [37] & 29 & 3.3 & 7 & 80 & 4 \\
\hline & {$[38]$} & 36 & 5.5 & 21.6 & 89 & 64 \\
\hline \multirow{3}{*}{ Patch } & {$[10]$} & 28 & 6.3 & 21 & - & 42 \\
\hline & [39] & 29 & 6 & 13 & 75 & 8 \\
\hline & {$[40]$} & 28 & 2.6 & 11 & 70 & - \\
\hline
\end{tabular}

\section{Conclusions}

In this work, a mm-wave cylindrical dielectric resonant antenna (CDRA) array is presented using a new LTCC stack that ensures precision and ease of alignment. The array antenna consists of 16 single element cylindrical DR antenna (CDRA) operating at $28 \mathrm{GHz}$ for the $5 \mathrm{G}$ applications. The array is fed by an inverted microstrip corporate feeding network. Both the feeding network and the CDRA array are fabricated in the same LTCC process, ensuring cost effectiveness and high precision, thanks to the addition of a grounded and grooved superstrate. Measurement results show an impedance bandwidth of $9.81 \%$ around $28.52 \mathrm{GHz}$ with a maximum gain of $15.68 \mathrm{dBi}$ and an efficiency of $88 \%$. These results are in excellent agreement with simulations and the slight discrepancies between the two are attributable to inherent variability that can be expected in a single run fabrication using LTCC due mainly to small shrinkage factor variation. With its compact size and the precision of its fabrication process, the proposed antenna is a good candidate for mm-wave applications.

Author Contributions: M.N.: Conceptualization, formal analysis, methodology, software, writing-review and editing; A.K.: supervision, writing-review and editing. All authors have read and agreed to the published version of the manuscript. 
Funding: This research work was partially been supported by the Natural Sciences and Engineering Research Council of Canada (NSERC).

Institutional Review Board Statement: Not applicable.

Informed Consent Statement: Not applicable.

Data Availability Statement: Not applicable.

Acknowledgments: The authors would like to thank the Ferro Corporation for supporting this research.

Conflicts of Interest: The authors declare no conflict of interest.

\section{References}

1. Palomares-Caballero, A.; Alex-Amor, A.; Valenzuela-Valdes, J.; Padilla, P. Millimeter-Wave 3-D-Printed Antenna Array Based on Gap-Waveguide Technology and Split E-Plane Waveguide. IEEE Trans. Antennas Propag. 2021, 69, 164-172. [CrossRef]

2. Yang, Q.; Gao, S.; Luo, Q.; Wen, L.; Ban, Y.-L.; Yang, X.; Ren, X.; Wu, J. Cavity-Backed Slot-Coupled Patch Antenna Array With Dual Slant Polarization for Millimeter-Wave Base Station Applications. IEEE Trans. Antennas Propag. 2020, 69, 1404-1413. [CrossRef]

3. Mrnka, M.; Cupal, M.; Raida, Z.; Pietrikova, A.; Kocur, D. Millimetre-wave dielectric resonator antenna array based on directive LTCC elements. IET Microw. Antennas Propag. 2018, 12, 662-667. [CrossRef]

4. Haraz, O.M.; Elboushi, A.; Alshebeili, S.A.; Sebak, A.R. Dense dielectric patch array antenna with improved radiation characteristics using ebg ground structure and dielectric superstrate for future $5 \mathrm{G}$ cellular networks. IEEE Access 2014, 2, 909-913. [CrossRef]

5. Khalily, M.; Tafazolli, R.; Xiao, P.; Kishk, A.A. Broadband mm-Wave Microstrip Array Antenna with Improved Radiation Characteristics for Different 5G Applications. IEEE Trans. Antennas Propag. 2018, 66, 4641-4647. [CrossRef]

6. Meredov, A.; Klionovski, K.; Shamim, A. Screen-Printed, Flexible, Parasitic Beam-Switching Millimeter-Wave Antenna Array for Wearable Applications. IEEE Open J. Antennas Propag. 2019, 1, 2-10. [CrossRef]

7. Abohmra, A.; Jilani, F.; Abbas, H.; Ghannam, R.; Heidari, H.; Imran, M.A.; Abbasi, Q.H. Low-profile Flexible Perovskite based Millimetre Wave Antenna. In Proceedings of the IEEE MTT-S 2019 International Microwave Biomedical Conference, Nanjing, China, 6-8 May 2019.

8. Ashraf, N.; Sebak, A.R.; Kishk, A.A. Packaged Microstrip Line Feed Network on a Single Surface for Dual-Polarized 2N $\times 2 \mathrm{M}$ ME-Dipole Antenna Array. IEEE Antennas Wirel. Propag. Lett. 2020, 19, 596-600. [CrossRef]

9. Dzagbletey, P.A.; Jung, Y.B. Stacked microstrip linear array for millimeter-wave 5G baseband communication. IEEE Antennas Wirel. Propag. Lett. 2018, 17, 780-783. [CrossRef]

10. Cheon, Y.; Kim, Y. Stripline-fed aperture-coupled patch array antenna with reduced sidelobe. Electron. Lett. 2015, 51, 1402-1403. [CrossRef]

11. Alkaraki, S.; Gao, Y. Mm-Wave Low-Cost 3D Printed MIMO Antennas with Beam Switching Capabilities for 5G Communication Systems. IEEE Access 2020, 8, 32531-32541. [CrossRef]

12. Ntawangaheza, J.d.D.; Sun, L.; Yang, C.; Pang, Y.; Rushingabigwi, G. Thin-Profile Wideband and High-Gain Microstrip Patch Antenna on a Modified AMC. IEEE Antennas Wirel. Propag. Lett. 2019, 18, 2518-2522. [CrossRef]

13. Ta, S.X.; Park, I. Low-Profile Broadband Circularly Polarized Patch Antenna Using Metasurface. IEEE Trans. Antennas Propag. 2015, 63, 5929-5934. [CrossRef]

14. Maruyama, S.; Fukusako, T. An interpretative study on circularly polarized patch antenna using artificial ground structure. IEEE Trans. Antennas Propag. 2014, 62, 5919-5924. [CrossRef]

15. Oh, K.H.; Song, J.I. Investigation of surface-wave reduction in UC-PBG patch antenna by using a transient electrooptic near-field mapping technique. IEEE Trans. Antennas Propag. 2006, 54, 3602-3607. [CrossRef]

16. Chang, W.; Jung, D.Y.; Park, C.S. A surface wave reduced higher mode circular patch antenna for 60GHz LTCC SiP. In Proceedings of the Asia-Pacific Microwave Conference, Suzhou, China, 4-7 December 2005; Volume 4, pp. 3-5.

17. Petosa, A.; Ittipiboon, A. Dielectric resonator antennas: A historical review and the current state of the art. IEEE Antennas Propag. Mag. 2010, 52, 91-116. [CrossRef]

18. Kishk, A.A. Dielectric resonator antenna, a candidate for radar applications. In Proceedings of the 2003 IEEE Radar Conference (Cat. No. 03CH37474), Huntsville, AL, USA, 8 May 2003; pp. 258-264.

19. Lamminen, A.E.I.; Vimpari, A.R.; Saily, J. UC-EBG on LTCC for 60-GHz Frequency Band Antenna Applications. IEEE Trans. Antennas Propag. 2009, 57, 2904-2912. [CrossRef]

20. Abdallah, M.S.; Wang, Y.; Abdel-Wahab, W.M.; Safavi-Naeini, S. Design and Optimization of SIW Center-Fed Series Rectangular Dielectric Resonator Antenna Array with $45^{\circ}$ Linear Polarization. IEEE Trans. Antennas Propag. 2018, 66, 23-31. [CrossRef]

21. Mrnka, M.; Raida, Z. Enhanced-Gain Dielectric Resonator Antenna Based on the Combination of Higher-Order Modes. IEEE Antennas Wirel. Propag. Lett. 2016, 15, 710-713. [CrossRef]

22. Kishk, A.A. Directive dielectric resonator antenna excited by probe or narrow slot. In Proceedings of the 2012 IEEE Radio and Wireless Symposium, Santa Clara, CA, USA, 15-18 January 2012; pp. 387-390.

23. Al-Alem, Y.; Kishk, A.A. Wideband Millimeter-Wave Dielectric Resonator Antenna with Gain Enhancement. IEEE Antennas Wirel. Propag. Lett. 2019, 18, 2711-2715. [CrossRef] 
24. Mousavi, S.H.; Kouki, A.B. Highly Compact VHF/UHF Dual-Band/Dual-Function LTCC Circuits: Application to Avionic Systems. IEEE Trans. Components, Packag. Manuf. Technol. 2016, 6, 12-22. [CrossRef]

25. Isapour, A.; Kouki, A. Vertical LTCC Integrated Rectangular Waveguide and Transitions for Millimeter-Wave Applications. IEEE Trans. Microw. Theory Tech. 2019, 67, 868-882. [CrossRef]

26. Niayesh, M.; Kouki, A. A LTCC-based Loaded Dielectric Resonant Antenna. In 2020 IEEE International Symposium on Antennas and Propagation and North American Radio Science Meeting, Montreal, QC, Canada, 5-10 July 2020; pp. 507-508.

27. Petosa, A. Dielectric Resonator Antenna Handbook; Artech House: Norwood, MA, USA, 2007; Available online: https://ieeexplore. ieee.org/document/9101088 (accessed on 10 May 2021).

28. Dash, S.K.K.; Khan, T.; Antar, Y.M.M. A state-of-art review on performance improvement of dielectric resonator antennas. Int. J. RF Microw. Comput. Eng. 2018, 28, e21270. [CrossRef]

29. Svedin, J.; Huss, L.G.; Karlén, D.; Enoksson, P.; Rusu, C. A micromachined 94 GHz dielectric resonator antenna for focal plane array applications. IEEE MTT-S Int. Microw. Symp. Digest 2007, 1375-1378. [CrossRef]

30. Kumar, A.V.; Yohannan, J.; Lonappan, A.; Bindu, G.; Thomas, V.; Hamsakkutty, V.; Mathew, K.T. Microstripline fed circular sector dielectric resonator antenna. In Proceedings of the IEEE Antennas and Propagation Society, AP-S International Symposium (Digest), Washington, DC, USA, 3-8 July 2005; Volume 2, pp. 192-195. [CrossRef]

31. Dash, S.K.K.; Khan, T.; De, A. Dielectric resonator antennas: An application oriented survey. Int. J. RF Microw. Comput. Eng. 2017, 27, e21069. [CrossRef]

32. Kishk, A.A.; Glisson, A.W.; Kajfez, D. Computed resonant frequency and far fields of isolated dielectric discs. In Proceedings of the AP-S International Symposium (Digest) (IEEE Antennas and Propagation Society), Ann Arbor, MI, USA, 28 June-2 July 1993; Volume 1, pp. 408-411.

33. Pozar, D.M.; Targonski, S.D. Improved coupling for aperture coupled microstrip antennas. Electron. Lett. 1991, 27, 1129-1131. [CrossRef]

34. Pozar, D.M. Microwave Engineering; John Wiley \& Sons: Hoboken, NJ, USA, 2012.

35. LTCC Lacime. Available online: https://en.etsmtl.ca/unites-de-recherche/ltcc/accueil (accessed on 14 April 2021).

36. Abdel-Wahab, W.M.; Abdallah, M.; Anderson, J.; Wang, Y.; Al-Saedi, H.; Safavi-Naeini, S. SIW-Integrated Parasitic DRA Array: Analysis, Design, and Measurement. IEEE Antennas Wirel. Propag. Lett. 2019, 18, 69-73. [CrossRef]

37. Sharawi, M.S.; Podilchak, S.K.; Hussain, M.T.; Antar, Y.M.M. Dielectric resonator based MIMO antenna system enabling millimetre-wave mobile devices. IET Microw. Antennas Propag. 2017, 11, 287-293. [CrossRef]

38. Abdel-Wahab, W.M.; Wang, Y.; Safavi-Naeini, S. SIW Hybrid Feeding Network-Integrated 2-D DRA Array: Simulations and Experiments. IEEE Antennas Wirel. Propag. Lett. 2016, 15, 548-551. [CrossRef]

39. Stanley, M.; Huang, Y.; Loh, T.; Xu, Q.; Wang, H.; Zhou, H. A high gain steerable millimeter-wave antenna array for 5G smartphone applications. In Proceedings of the 2017 11th European Conference on Antennas and Propagation (EUCAP), Paris, France, 19-24 March 2017; pp. 1311-1314.

40. Zhou, H. Phased array for millimeter-wave mobile handset. In Proceedings of the 2014 IEEE Antennas and Propagation Society International Symposium (APSURSI), Memphis, TN, USA, 6-11 July 2014; pp. 933-934. 